\title{
Guest leakage from ZIF-8 particles under drug delivery conditions: quantitative characterization and guest-induced framework stabilization
}

Artem S. Poryvaev, ${ }^{a, b}$ Anastasiya A. Yazikova, ${ }^{a, b}$ Daniil M. Polyukhov, ${ }^{a}$ Olga A. Chinak, ${ }^{c}$ Vladimir A. Richter, ${ }^{c}$ Olesya A. Krumkacheva, ${ }^{a^{*}}$ Matvey V. Fedin ${ }^{a^{*}}$

${ }^{a}$ International Tomography Center SB RAS, Novosibirsk, 630090, Russia

${ }^{\mathrm{b}}$ Novosibirsk State University, Novosibirsk, 630090, Russia

'Institute of Chemical Biology and Fundamental Medicine, Novosibirsk, 630090, Russia

Corresponding Authors: olesya@tomo.nsc.ru (O.A.K.), mfedin@tomo.nsc.ru (M.V.F.)

High loading of guest molecules was approved via analysis of EPR data for bare MOF. First, we have measured the amount of spin probe per sample weight. The amount found was 1 nitroxide molecule per 6 ZIF-8 cavities.

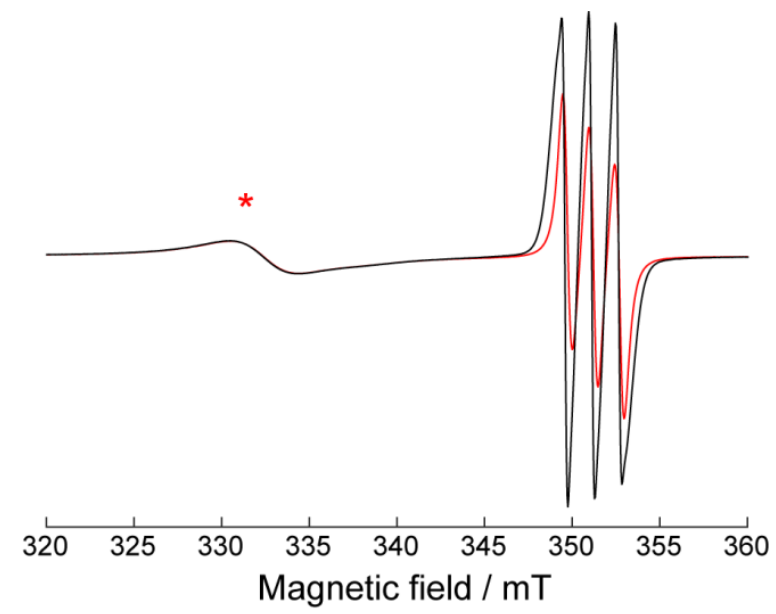

Figure S1. X-band room-temperature CW EPR spectra of TEMPO@ZIF-8 (black) and TEMPO dissolved in toluene (red). Spectra were measured together with copper(II) sulphate crystal (in separate tube) as a reference. Reference signal is marked by asterisk. All spectra are normalized to the reference signal. 
a)

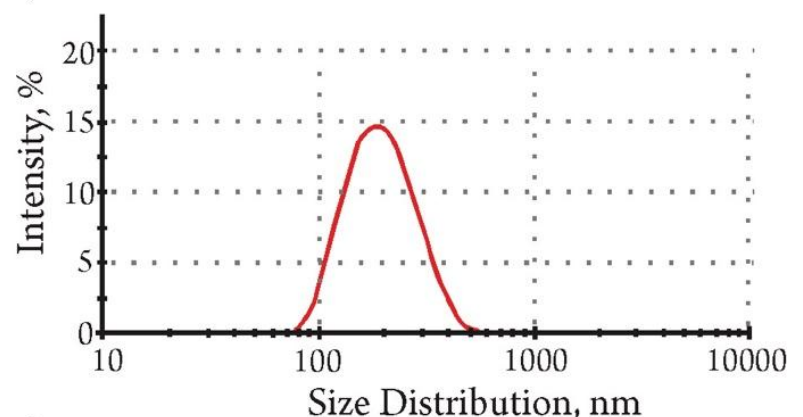

b)

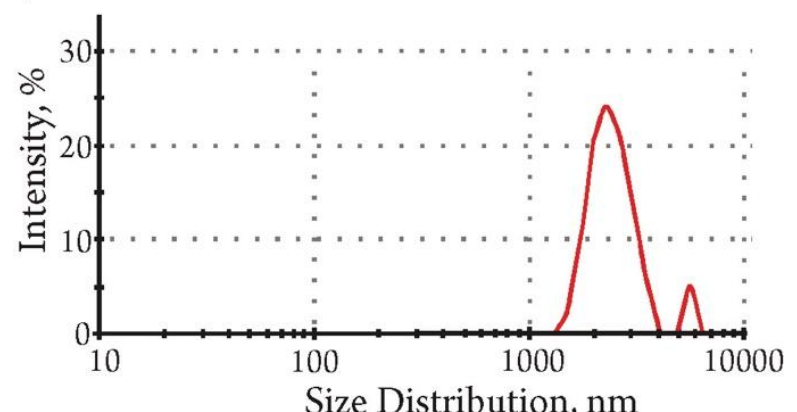

Figure S2. Particle size distribution curves of ZIF-8 nanoparticles (a) and microparticles (b) in water measured by DLS.

We have compared EPR spectra of TEMPO@ZIF-8 samples open to air and evacuated (10 ${ }^{-3}$ mbar) and found only minor line narrowing (Fig. S3). This means that the EPR signal of nitroxide in ZIF8 cavity is broadened mainly by interactions with other nitroxides in the MOF, confirming high concentration of radicals.

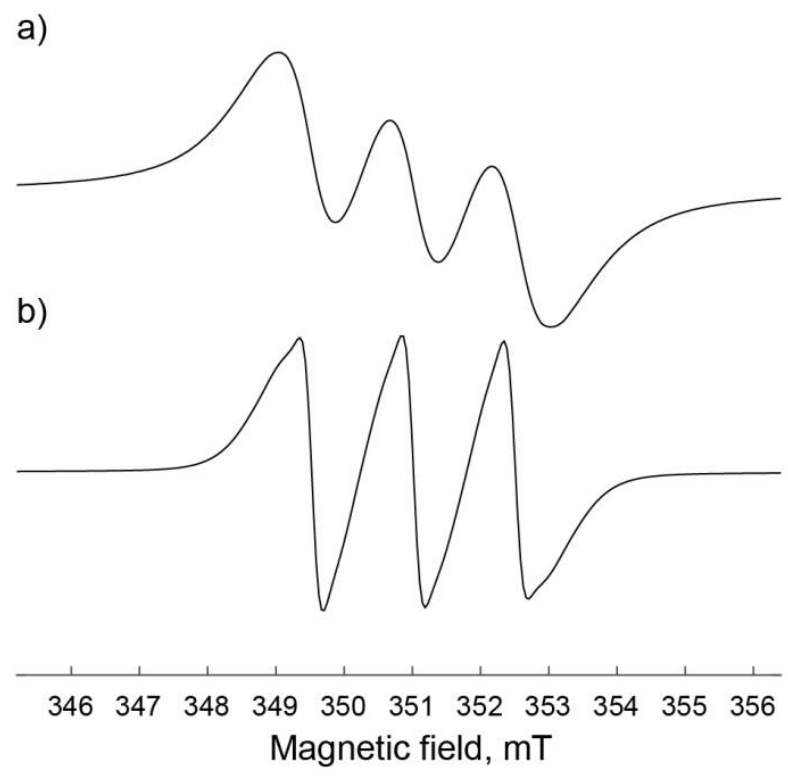

Figure S3. X-band room-temperature CW EPR spectra of TEMPO@ZIF-8: containing air(a) and after evacuation for 1 hour(b). All spectra are normalized.

EPR spectrum of TEMPO dissolved in water $(1 \mathrm{mM})$ is the same as narrow-line fraction observed in spectra after nitroxides escape during ZIF-8 dissolution (Fig.S4). Therefore, we used the same parameters to simulate EPR spectrum of TEMPO dissolved in water and for TEMPO released from ZIF-8 cavities into a bulk (Table S2). 


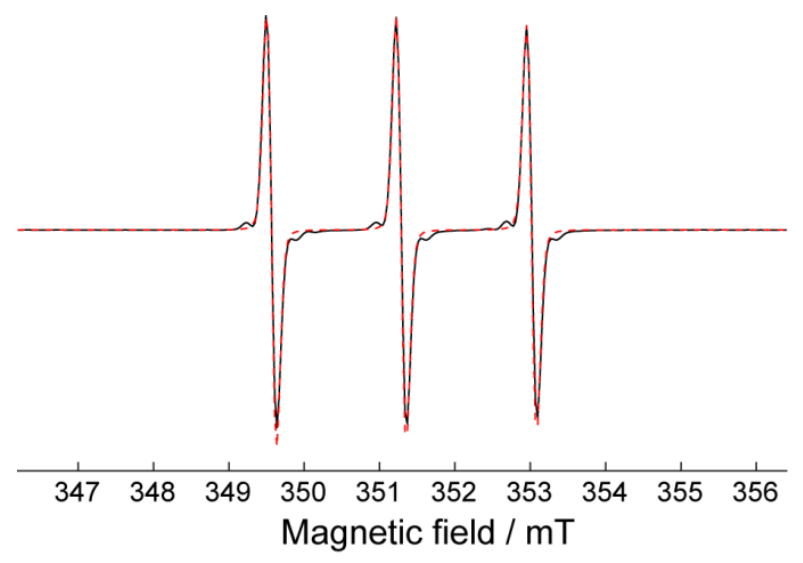

Figure S4. X-band room-temperature CW EPR spectra of TEMPO dissolved in water. Simulated EPR spectra are shown as dotted red lines. All spectra are normalized.

Determination of released guest amount was carried out after addition of different amount of PBS (1X) to ZIF-8 suspension. For better evaluation of radical content in solution we have simulated amounts of both fractions in $1^{\text {st }}$ integral mode of EPR spectra (Fig.S5). The simulation used leastsquare fitting of the whole spectrum, while the agreement in central region (marked by blue rectangle in Fig.S5) was prioritized.

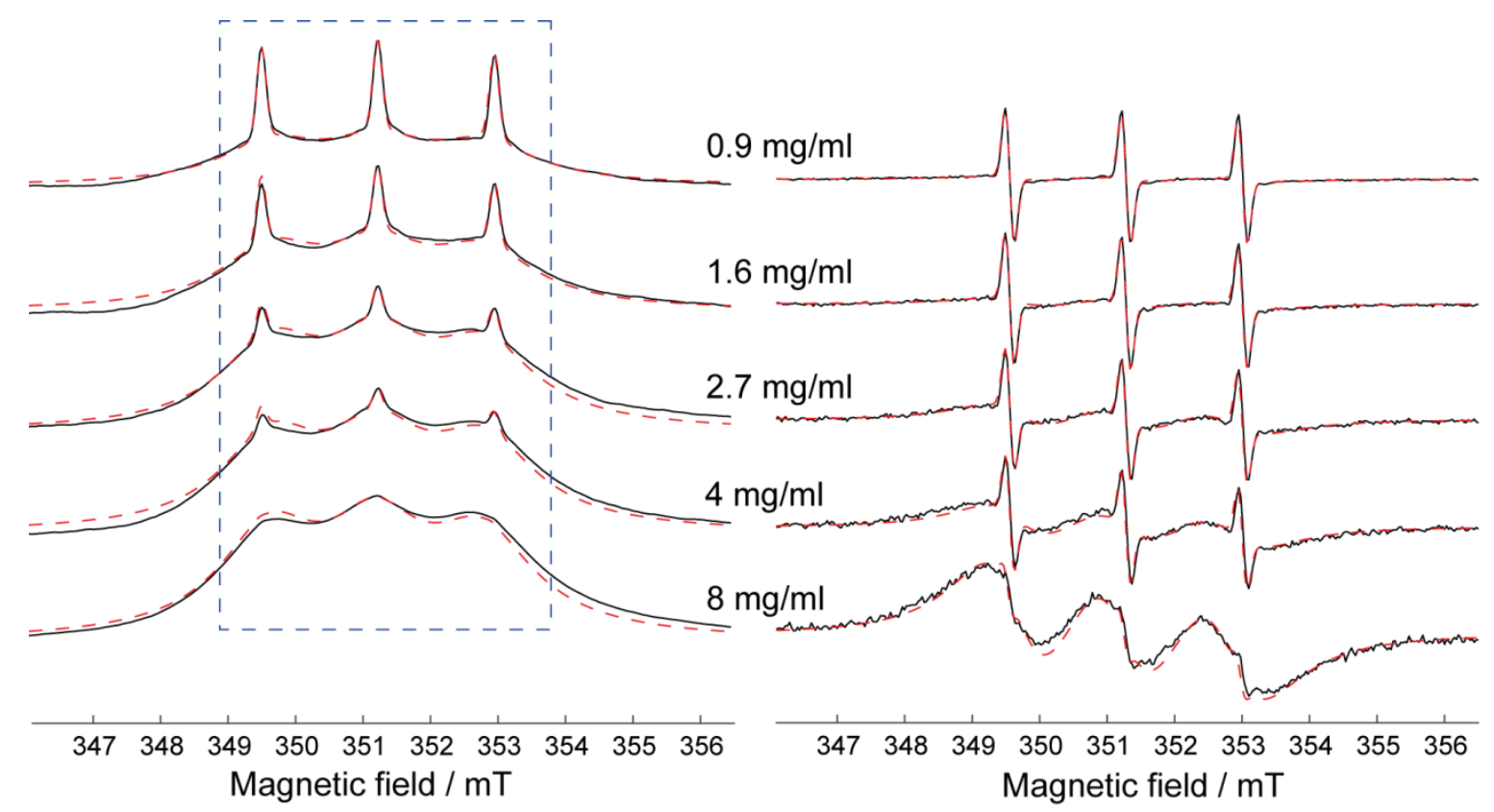

Figure S5. X-band room-temperature CW EPR spectra of TEMPO@ZIF-8 diluted with different amount of PBS are shown by black lines in left column. $1^{\text {st }}$ integrals of the same EPR spectra are shown in right column. Simulated EPR spectra are shown as dotted red lines. Field of contribution evaluation was marked by blue dotted square. All spectra are normalized.

Contrary to ZIF-8 degradation in water, we have found fast kinetics of particles decomposition in PBS (Fig. S6). 


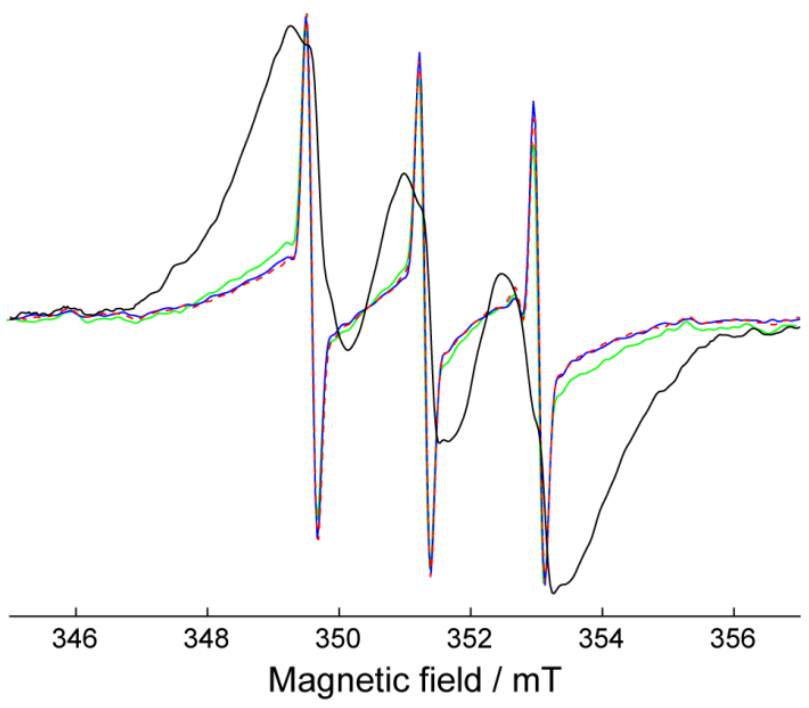

Figure S6. X-band room-temperature CW EPR spectra of TEMPO@ZIF-8 diluted by PBS. Spectrum measured immediately after addition of PBS (a) is shown by green line, after 2 hour - blue line, next day - red dotted line. Spectrum of ZIF-8 water based suspension measured before addition of PBS is shown by black line. All spectra are normalized.

Table S1 reports the data obtained by the analysis of $1^{\text {st }}$ integral EPR spectra for ZIF- 8 suspension diluted by PBS. Spectroscopic parameters used in simulations are listed in Table S2.

Table S1. Amount of released guest from TEMPO@ZIF-8 particles after addition different amount of PBS.

\begin{tabular}{|c|c|}
\hline $\begin{array}{c}\text { Concentration of ZIF-8 } \\
\text { particle in suspension, } \mathbf{~ m g / m l}\end{array}$ & $\begin{array}{c}\text { amount of released guest molecules } \\
\text { after addition of PBS, \% }\end{array}$ \\
\hline 4 & $1.8 \pm 0.5$ \\
\hline 2.7 & $2.7 \pm 0.5$ \\
\hline 1.6 & $8 \pm 2$ \\
\hline 0.9 & $14 \pm 3$ \\
\hline
\end{tabular}

Table S2. Best-fit parameters for X-band CW EPR spectra of TEMPO@ZIF-8 suspension and TEMPO released into water.

\begin{tabular}{|c|c|c|c|c|}
\hline Temperature / K & {$\left[\mathbf{g}_{\mathbf{x x}} \mathbf{g}_{\mathbf{y y}} \mathbf{g}_{\mathbf{z z}}\right]$} & $\begin{array}{c}{\left[\mathbf{A}_{\mathbf{x x}} \mathbf{A}_{\mathbf{y y}} \mathbf{A}_{\mathbf{z z}}\right] /} \\
\mathbf{m T}\end{array}$ & $\begin{array}{c}\tau_{\mathbf{c}} / \\
\mathbf{n s}\end{array}$ & $\begin{array}{c}\text { Line width / } \\
\mathbf{m T}\end{array}$ \\
\hline TEMPO@ZIF-8 & {$[2.0115,2.0086,2.0035]$} & {$[0.60,0.60,3.55]$} & 0.02 & 1.73 \\
\hline TEMPO in water & {$[2.0115,2.0086,2.0035]$} & {$[0.73,0.73,3.73]$} & 0.01 & 0.14 \\
\hline
\end{tabular}


Determination of the released guest amount was carried out after addition of different amount of FBS or albumin solution to ZIF-8 suspension. For better evaluation of radical content in solution we have simulated amount of both fraction in $1^{\text {st }}$ integral mode of EPR spectra (Fig. S7).

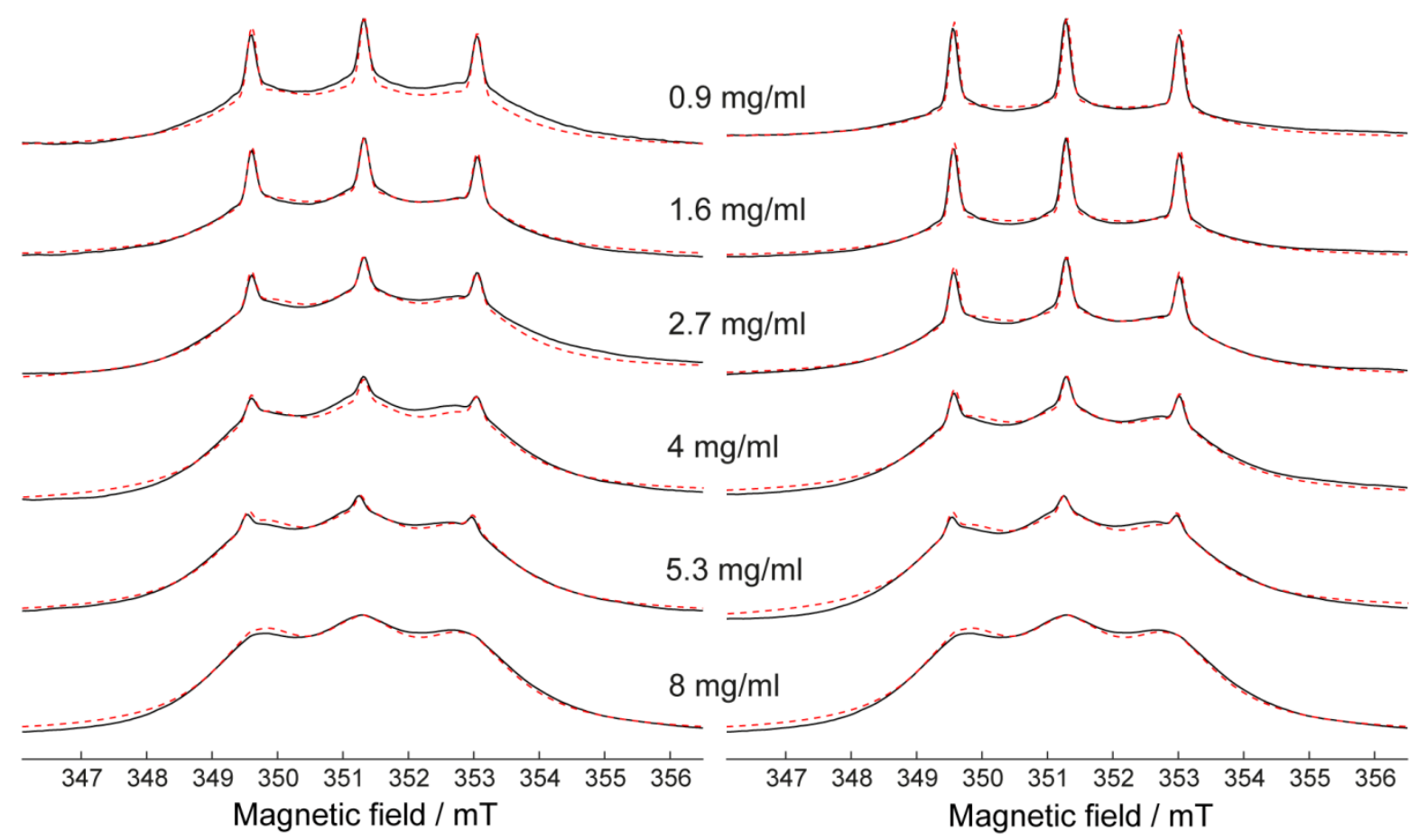

Figure S7. $1^{\text {st }}$ integrals of X-band room-temperature CW EPR spectra of TEMPO@ZIF-8 diluted with different amount of FBS are shown by black lines in the left column. Right column refers to TEMPO@ZIF-8 diluted with different amount of human serum albumin solution. Simulated EPR spectra are shown in red. All spectra are normalized.

Table S3 reports the data obtained by the analysis of ZIF-8 suspension diluted by FBS. Parameters used in simulations are listed in Table S2.

Table S3. Amount of released guest from TEMPO@ZIF-8 particles after dilution with different amount of FBS or different albumin solution.

\begin{tabular}{|c|c|c|c|c|}
\hline $\begin{array}{c}\text { Concentration of } \\
\text { ZIF-8 particle in } \\
\text { suspension, mg/ml }\end{array}$ & $\begin{array}{c}\text { Amount of } \\
\text { released guest } \\
\text { molecules after } \\
\text { addition of FBS, } \\
\text { \% }\end{array}$ & $\begin{array}{c}\text { Amount of released } \\
\text { guest molecules after } \\
\text { addition of } \\
\text { pharmaceutical } \\
\text { albumin solution, \% }\end{array}$ & $\begin{array}{c}\text { Amount of released } \\
\text { guest molecules } \\
\text { after addition of } \\
\text { human serum } \\
\text { albumin, \% }\end{array}$ & $\begin{array}{c}\text { Amount of released } \\
\text { guest molecules } \\
\text { after addition of } \\
\text { bovine serum } \\
\text { albumin, \% }\end{array}$ \\
\hline 5.3 & $1.4 \pm 0.3$ & $1.8 \pm 0.4$ & $1.3 \pm 0.3$ & - \\
\hline 4 & $2.2 \pm 0.4$ & $3.3 \pm 0.7$ & $4.3 \pm 0.9$ & - \\
\hline 2.7 & $3.7 \pm 0.7$ & $7 \pm 1$ & $7 \pm 1$ & - \\
\hline 1.6 & $7 \pm 1$ & $13 \pm 3$ & $11 \pm 2$ & - \\
\hline 0.9 & $9 \pm 1$ & $17 \pm 3$ & $11 \pm 2$ & $11 \pm 2$ \\
\hline
\end{tabular}

ZIF-8 degradation in FBS has a similar decomposition kinetics compared to that in PBS, showing fast guest release and no further changes (Fig. S8). 


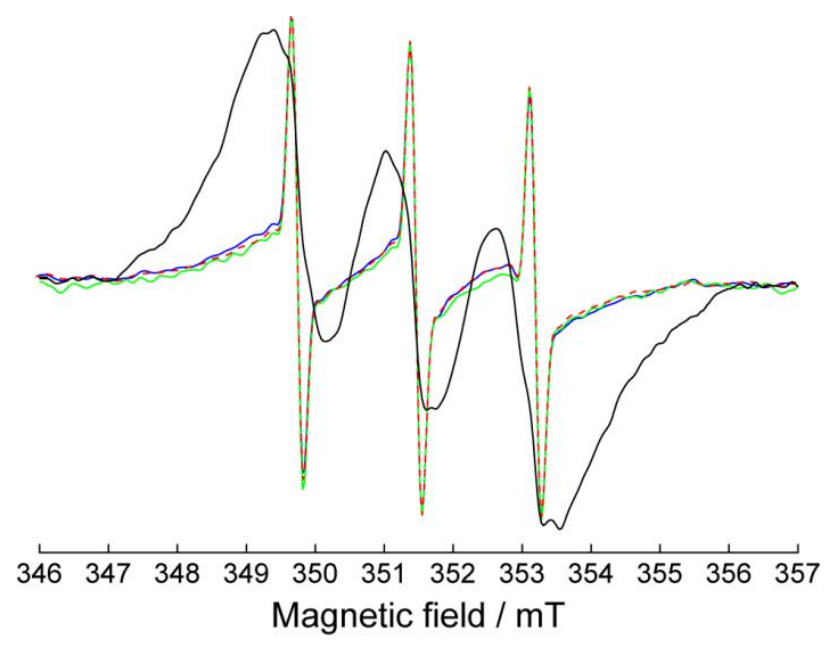

Figure S8. X-band room-temperature CW EPR spectra of TEMPO@ZIF-8 diluted by FBS. Spectrum measured immediately after addition of FBS is shown by blue lines, after 2 hour - green line, next day - red line. Spectrum of ZIF-8 water based suspension measured before addition of FBS is shown by black line. All spectra are normalized.

Mixing of ZIF-8 suspension with exosome or liposome solution showed insignificant guest molecules release (Fig.S9b). However, the addition of albumin solution to ZIF-8 suspension preliminary mixed with exosomes or liposomes, leads to a similar guest release profile as in the case of pure particles (Fig.S9).

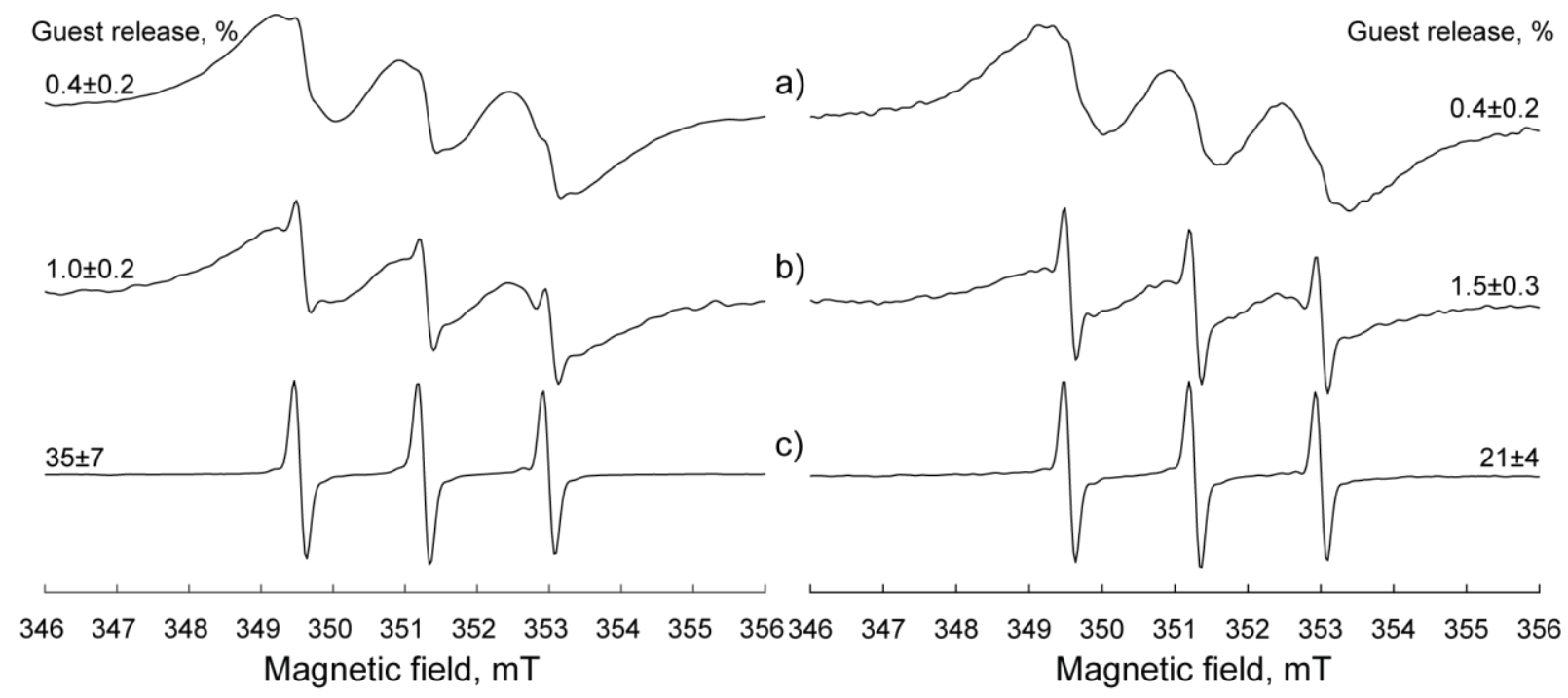

Figure S9. X-band room-temperature CW EPR spectra of TEMPO@ZIF-8 water based suspension (a) mixed with exosome (left column) or liposome (right column) solution (b) then diluted with albumin solution to final concentration $1.6 \mathrm{mg} / \mathrm{ml}$ (c). All spectra are normalized. 
Table S4. Amount of released guest from TEMPO@ZIF-8 particles after dilution with different amount of albumin solution treated with stearic acid or $o$-xylene.

\begin{tabular}{|c|c|c|}
\hline $\begin{array}{c}\text { Concentration of } \\
\text { ZIF-8 particle in } \\
\text { suspension, } \\
\text { mg/ml }\end{array}$ & $\begin{array}{c}\text { Amount of released guest } \\
\text { molecules after addition of } \\
\text { albumin solution treated with } \\
\text { stearic acid, \% }\end{array}$ & $\begin{array}{c}\text { Amount of released guest } \\
\text { molecules after addition of } \\
\text { albumin solution treated } \\
\text { with o-xylene, \% }\end{array}$ \\
\hline 5.3 & $1.2 \pm 0.2$ & $0.2 \pm 0.3$ \\
\hline 4 & $2.8 \pm 0.6$ & $0.4 \pm 0.3$ \\
\hline 2.7 & $7 \pm 1$ & $2.7 \pm 0.5$ \\
\hline 1.6 & $18 \pm 4$ & $5 \pm 1$ \\
\hline 0.9 & $35 \pm 7$ & $9 \pm 2$ \\
\hline
\end{tabular}

Table S5. Amount of released guest from (o-xylene+TEMPO@ZIF-8) particles after dilution with different amount of FBS.

\begin{tabular}{|c|c|}
\hline $\begin{array}{c}\text { Concentration of ZIF- } \\
\text { 8 particle in } \\
\text { suspension, mg/ml }\end{array}$ & $\begin{array}{c}\text { Amount of released guest } \\
\text { molecules after addition } \\
\text { of FBS, \% }\end{array}$ \\
\hline Initial (FBS free) & $1.3 \pm 0.3$ \\
\hline 5.33 & $0.9 \pm 0.3$ \\
\hline 4 & $1.9 \pm 0.3$ \\
\hline 2.7 & $1.3 \pm 0.3$ \\
\hline 1.6 & $0.9 \pm 0.3$ \\
\hline 0.9 & $0.6 \pm 0.3$ \\
\hline
\end{tabular}

Suspension containing ZIF-8 nanoparticles was studied by EPR spectroscopy as prepared and after dilution with water, PBS and FBS (Table S6).

Table S6. Amount of released guest from TEMPO@ZIF-8 nanoparticles after dilution with different diluent to a final concentration $0.9 \mathrm{mg} / \mathrm{ml}$.

\begin{tabular}{|c|c|}
\hline Diluent & $\begin{array}{c}\text { Amount of released guest } \\
\text { molecules, \% }\end{array}$ \\
\hline- & $1.3 \pm 0.3$ \\
\hline water & $13 \pm 3$ \\
\hline PBS & $>80$ \\
\hline FBS & $>80$ \\
\hline
\end{tabular}




\section{References}

(1) Polyukhov, D. M.; Poryvaev, A. S.; Gromilov, S. A.; Fedin, M. V. Precise Measurement and Controlled Tuning of Effective Window Sizes in ZIF-8 Framework for Efficient Separation of Xylenes. Nano Lett. 2019, 19, 6506-6510.

(2) Cheng, G.; Li, W.; Ha, L.; Han, X.; Hao, S.; Wan, Y.; Wang, Z.; Dong, F.; Zou, X.; Mao, Y.; et al. Self-Assembly of Extracellular Vesicle-like Metal-Organic Framework Nanoparticles for Protection and Intracellular Delivery of Biofunctional Proteins. J. Am. Chem. Soc. 2018, 140, 7282-7291.

(3) Stoll, S.; Schweiger, A. EasySpin, a Comprehensive Software Package for Spectral Simulation and Analysis in EPR. J. Magn. Reson. 2006, 178, 42-55. 